\title{
A final message from Prof. Paolo Palange at the end of his mandate as ERS School Chair 2008-2011
}

When I started my mandate as Chair of the European Respiratory Society (ERS) School, I had several objectives in mind. First of all, my aim was to carry on the very successful Adult and Paediatric HERMES (Harmonised Education in Respiratory Medicine for European Specialists) projects initiated by my predecessor Patricia Haslam. The objective of HERMES is to provide a framework for the development of consensus standards and collective documents and activities, a very important initiative for respiratory medical education (fig. 1).

The Adult HERMES Task Force is now nearing its end with the publication of the document on "Criteria for accreditation of ERS European Training Centres" in December 2010.

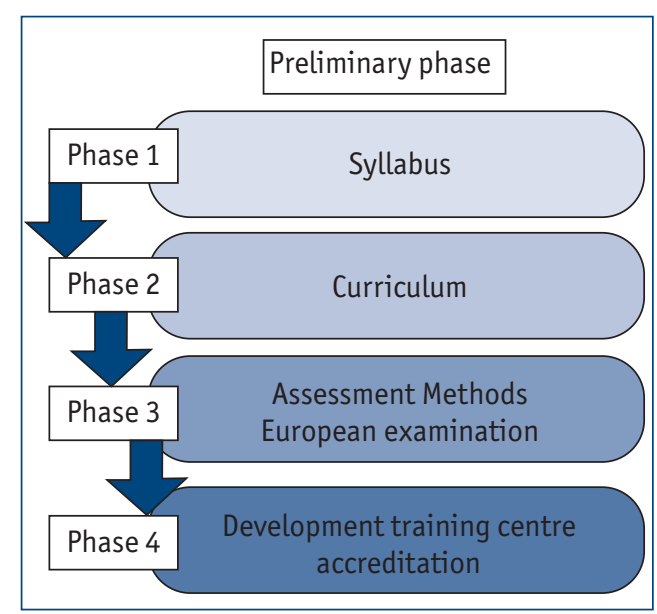

Figure 1

HERMES project phases.
However, activities emerging from the Adult HERMES project will carry on with the Adult HERMES examination, which continues to gain recognition from countries both within and outside Europe, and also the potential establishment of a joint accreditation process with ERS and EBAP to accredit training centres in adult respiratory medicine. In addition, for the first time, during the ERS Annual Congress in Amsterdam, the Paediatric HERMES examination in respiratory medicine will take place. I have to acknowledge the great work done by the Examination Committee chaired by Konrad Bloch and the great support from Robert Loddenkemper and Monika Gappa in chairing the HERMES Adult and Paediatric Task Forces.

The European Spirometry Driving Licence HERMES project was launched at the beginning of my mandate in 2008. Again, this HERMES project has taken great strides in the last three years publishing a training programme for a certified spirometry training programme, and a certification guidelines document. This project continues to develop under the leadership of the project chairs Brendan Cooper and Irene Steenbruggen.

During my mandate, two new HERMES projects I consider strategic for the future of the ERS, have been initiated: "HERMES Respiratory Sleep Disorders" and "HERMES Respiratory Critical Care". In this issue of Breathe, the Respiratory Sleep Syllabus is published. The syllabus of HERMES Respiratory Critical Care will be finalised soon by the task force members and published in early 2012. Since the launch of the adult

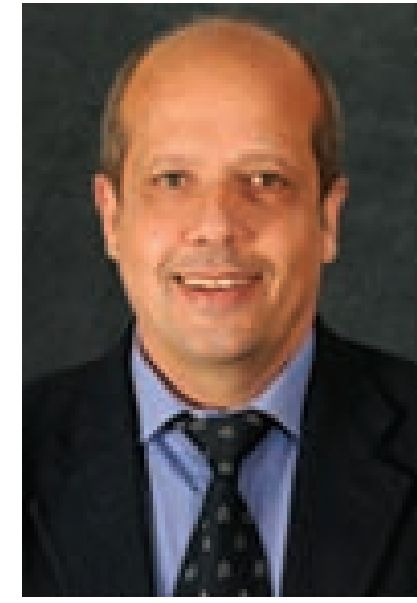

\section{P. Palange}

Competing interests None declared. 


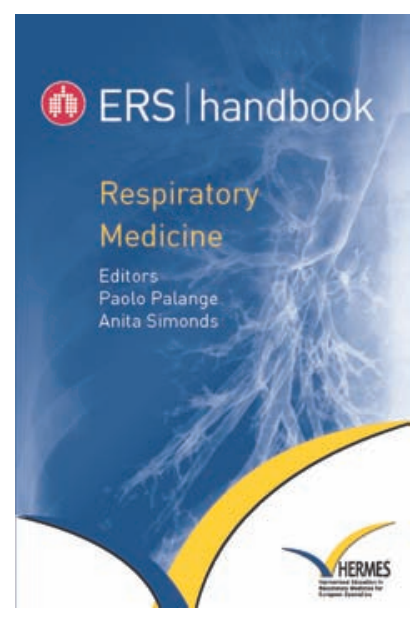

HERMES project in 2005, the HERMES initiative has continued to gain merit and esteem across the various speciality areas of respiratory medicine and there are now six active HERMES projects (fig. 2). I have to really thank the ERS leadership for supporting the School in these new important initiatives.

During the last three years, new educational activities have been developed, including educational videos, online modules and online clinical cases which can be viewed on the ERS education website (www.erseducation.org). This expansion of e-learning resources was possible because of the great work of Johan Verbraecken (director of elearning), Pascal Kurosinski and Ali Merzouk. At the same time state-of-the-art external courses have been organised under the guidance of Gernot Rohde, director of external courses. In support of the Adult HERMES examination, the HERMES Summer School which will take place in 2012 will be the first of its kind to help prepare candidates who wish to take the HERMES examination in adult respiratory medicine. The course programme will cover all important topics from the HERMES syllabus and include revision of supporting literature and MCQ questions.

Postgraduate Courses and Meet the Professor Seminars have been organised and developed during the ERS annual congresses under

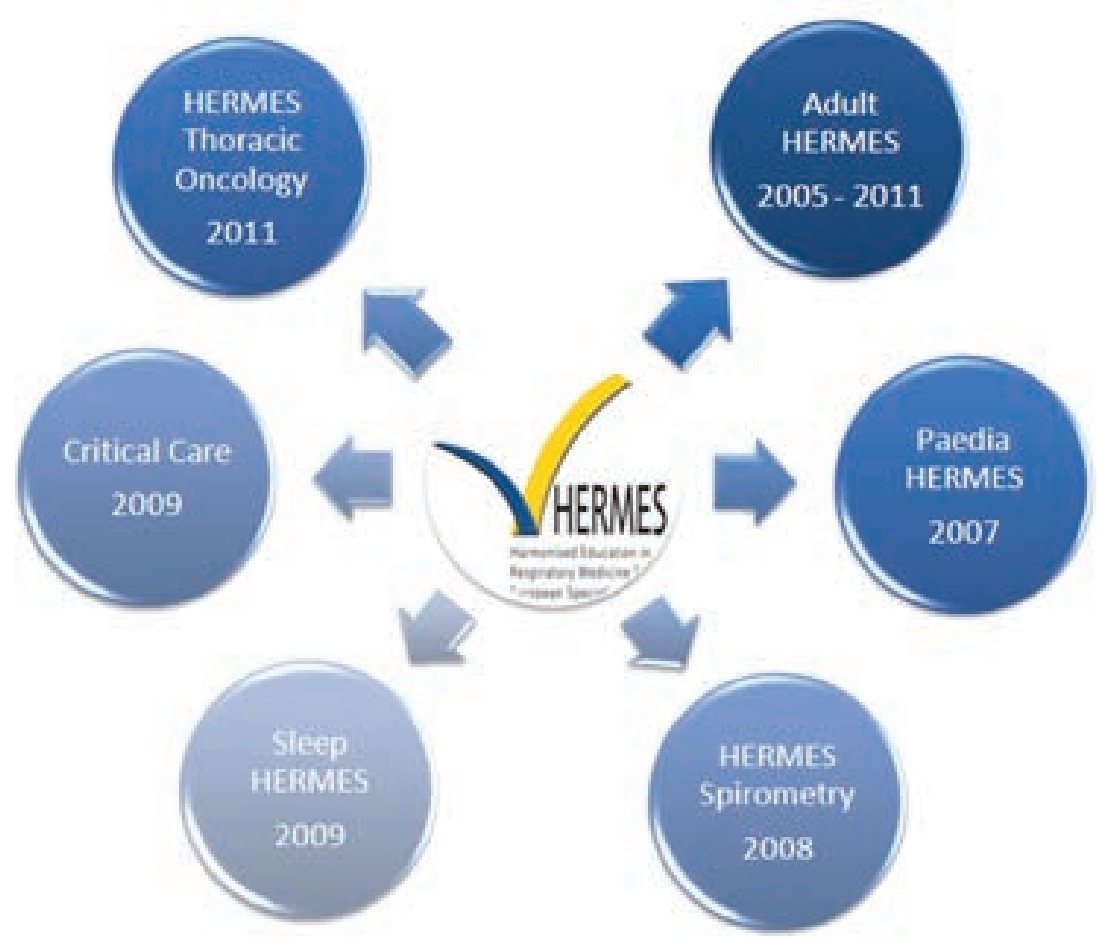

Figure 2

Active HERMES projects. the guidance of Mario Cazzola. More than 2,500 respiratory doctors attend ERS educational activities each year. At the 2011 ERS Annual Congress in Amsterdam, for the first time, four Early Morning Seminars, i.e. practical educational sessions, will be held on Monday and Tuesday.

Under the guidance of Leif Bjermer, the educational publication Breathe continues to be a highly appreciated educational journal publishing editorials, reviews and articles in key areas of respiratory medicine. The European Respiratory Monograph (ERM) has also been overseen by the school committee and Tobias Welte; and has recently begun being marketed in Turkey, China, Korea, Australia and Brazil.

Probably the greatest achievement during my mandate was the publication of the first edition of the ERS Handbook of Respiratory Medicine in 2010. The Handbook is a great success for the ERS School and for ERS. It was because of the great effort of the editors, authors, and Matt Broadhead and Pippa Powell from the ERS Publishing Department in Sheffield (UK) that, in 18 months, we were able to achieve this ambition. The future will see a second edition of the Handbook and two new handbooks: the "MCQ HERMES Examination Handbook" and the "ERS Respiratory Sleep Handbook". I have to really thank Anita Simonds and Sharon Mitchell for their great support in realising these very ambitious projects.

From the beginning of my mandate, I thought that there was a need for critical selfreflection on the current state of educational policies within the ERS School as well as determining future directions in respiratory medical education. For this reason the School organised the first ERS educational research seminar that was held in Dublin, Ireland, on the 3-4 June 2011. Experts in respiratory medicine and in medical education met to discuss the future trends and challenges in respiratory medical education. A summary report of the Dublin meeting is also presented in this issue of Breathe.

I want to leave you by saying that it has been a great privilege to work with so many highly motivated colleagues. I especially thank all the members of the School and Examination Committees. A special thanks to Tania Séverin, Sharon Mitchell, Amy Farr, Sandy Sutter, Julie-Lyn Noël, Alexandre Delage and Carine Pannetier for their great support and work in the ERS education department. It has been a great honour to serve as ERS School Committee Chair. I wish my successor Anita Simonds and our Society a great future of success! 


\section{New School Initiatives 2008-2011}

- Adult HERMES, Examination Committee and Criteria for European Training Centres Accreditation

- Paediatric HERMES, Updated Syllabus and Examination

- HERMES Spirometry Driving License, Training Programme and Certification Guidelines

- HERMES Respiratory Sleep Disorders, Task Force and Syllabus

- HERMES Critical Care, Task Force

- Educational videos, Online Modules, Online Clinical Cases

- ERS Handbook of Respiratory Medicine, $1^{\text {st }}$ Edition Barcelona 2010

- Early Morning Seminars, Amsterdam September 2011

\section{References}

1. Palange P, Simonds A, eds. ERS Handbook of Respiratory Medicine First Edn. European Respiratory Society, Sheffield, 2010.

2. Gappa M, Noël J-L, Séverin T, et al. Paediatric HERMES: a European syllabus in Paediatric Respiratory Medicine. Breathe 2009; 5: 237-247.

3. Gappa M, Paton J, Baraldi E, et al. Paediatric HERMES: update of the European Training Syllabus for Paediatric Respiratory Medicine. Eur Respir J 2009; 33: 464-465.

4. Gappa M, Noël J-L, Séverin T, et al. Paediatric HERMES: European Curriculum Recommendations for Training in Paediatric Respiratory Medicine. Breathe 2010; 7: 72-78.

5. Loddenkemper R, Séverin T, Mitchell S, et al. Adult HERMES: Criteria for Accreditation of ERS European Training Centres in Adult Respiratory Medicine. Breathe 2010; 7: 170-188.

6. Loddenkemper R, Séverin T, Mitchell S, et al. HERMES Criteria for Accreditation of European Training Centres: overcoming challenges of accreditation. Eur Respir J 2010; 36: 1239-1241.

7. Steenbruggen I, Mitchell S, Séverin T, et al. Spirometry HERMES: A European training programme and qualification in spirometry practice. Breathe 2011; 7: 259-275.

8. Steenbruggen I, Mitchell S, Séverin T, et al. Harmonising Spirometry Education with HERMES: training a new generation of qualified spirometry practitioners across Europe. Eur Respir J 2011; 37: 479-481.

9. De Backer W, Simonds A, Horn V, et al. Sleep HERMES: A European Core Syllabus in Respiratory Disorders during sleep. Breathe, September 2011 (in press).

10. De Backer W, Simonds A, Horn V, et al. Sleep HERMES: a European Training Project for Respiratory Sleep Medicine. Eur Respir J, September 2011 (in press). 